\title{
Mechanical Properties of Sago/Urea Formaldehyde Particleboard Affected by the Weight Fraction of Sago
}

\author{
Tay Chen Chiang ${ }^{1, a}$, Sinin Hamdan ${ }^{2, b}$, Mohd Shahril.Osman ${ }^{3, c}$ \\ 1,2 University Malaysia Sarawak, Faculty of engineering \\ ${ }^{3}$ University College of Technology Sarawak
}

\begin{abstract}
Sago processing industry in Sarawak-Mukah annually had generated huge amount of Sago waste. In order to reduce the waste from becoming a serious environment problem, researchers employ the sago waste combine with urea formaldehyde to create a good particleboard. This study examined the effect of weight fraction of Sago on the mechanical properties of Sago particleboard. Sago particles and urea formaldehyde (UF) were used as raw material in the fabrication process. The fabrication and testing method are based on JIS A 5908 standard. The samples were prepared based on different weight fraction of Sago and went through the tensile and impact test which had great influence on the particleboard performance and show that sago particles can be an alternative raw material in the manufacture of particleboards.
\end{abstract}

\section{Introduction}

Nowadays, the wood industry is increasingly becoming an important part of our lives. Researchers had come up with an idea of using the natural fibres mixed with thermoset or thermoplastic as composite to meet with the high demand of wood industry. Natural fibres like bamboo, coconut husk, cotton stalk, rice husk, pine needle, rice straw and non-edible grass are widely used in the composite industries [1]. The advantages and qualities of natural fibres are economical price, low density, high toughness, acceptable specific strength, recyclability, biodegradability and availability [2]. The fact available caused natural fibres have been used as raw materials in the composite industry and as an alternative raw materials in the manufacture of particleboards [2]. The application of composite can be used as the following item like: floor boards, boards for acoustic damping, shipping crates, pallets and furniture [3].

In Sarawak, Malaysia, the demand for Sago is increasing from year to year and it becomes the biggest sago starch processing industries state in Malaysia. The findings of a research show that it is estimated that around 7 tons of sago pith waste was produced daily from a single sago starch processing mill and were discharge into the river or burnt in field [4, 5]. Researchers had come up with an idea to overcome the environment pressure by utilization of Sago residues combine with the thermoset/ thermoplastic into a composite in order to benefits the environment and increase the attention of public about environmentally friendly products $[6,7]$.

The objective of this study is to investigate the effect of weight fraction on the mechanical properties and used the Sago waste as an alternative of raw material in the furniture industry.

\section{Experiment}

\subsection{Materials}

The Residues of Sago, bought from a local market in Mukah, were used as the raw materials in the Sago/UF particleboards. Urea formaldehyde (UF) with resin content of 51.5\% obtained from Hexzachem Sarawak Sdn. Bhd was used as the binder .1\% of NH4CI was mixed with UF during the mixing process and acted as the hardener.

\subsection{Particle preparation}

The Sago residues were dried under the sun for two days and went through the oven at $1050 \mathrm{C}$ for two hours to completely remove the moisture. Particles with the size of $0.6 \mathrm{~mm}, 1.18 \mathrm{~mm}$ and $2 \mathrm{~mm}$ were selected and used in this experiment. The sieving process was conducted using a sieving vibrator.

\subsection{Fabrication of Sago/UF particleboard}

Sago particles, Urea-formaldehyde (UF) and NH4CI were weighed based on the desired weight and placed into the mixing drum to undergo the mixing process. The core particles of Sago were mixed by spraying them with urea-formaldehyde and hardener to achieve a homogeneous distribution of adhesives on them. After the

Corresponding author: ${ }^{\mathrm{a}}$ chenchiang$@$,hotmail.my, ${ }^{\mathrm{b}}$ hsinin $@$,feng.unimas.my,${ }^{\mathrm{c}}$ mcmsoeh@gmail.com 
blending process, the sago particles were spread evenly into the $30 \mathrm{~cm}$ X $30 \mathrm{~cm}$ wooden mould using a stainless steel caul plate as the base.

A thin layer of silicon glass mat was placed onto the caul plate to prevent the panel from sticking to the plate during the hot press process. The mat was pre-pressed manually to consolidate the thickness. During the hot press process, the distance bars were placed at both sides of the mat in order to get the targeted board thickness. The mat went through the hot press process under the temperature of $1600 \mathrm{C}$. The pressure of the hot press machine was set at 40 bar for 2 minutes and then gradually decreased to 20 bar and 10 bar for 2 minutes respectively. After the hot press process, the boards were kept in the chamber with humidity of $65 \pm 5 \%$ and temperature $25 \pm 20 \mathrm{C}$ for two days curing process. The main purpose of curing is to stabile the particleboards with the stabilize condition for constant evaluation.

\subsection{Mechanical test}

Japanese Industrial Standard (JIS A 5908) for particleboards were used to evaluate the properties of the Sago particleboards [8]. The tensile specimens were prepared based on the dimension shown in Figure 1 and tests were conducted at $10 \mathrm{~mm} / \mathrm{min}$ loading speed. Mechanical tests on Young's Modulus and Tensile Strength were carried out using the Instron Universal testing machine (model 5566) . For the Charpy impact test, specimens were prepared based on the ASTM A370 standard with the width of $10 \mathrm{~mm} \mathrm{X}$ length of $55 \mathrm{~mm} \mathrm{X}$ thickness of $10 \mathrm{~mm}$ [9]. The Impact strength of the particleboard was measured using 50J Charpy impact tester LS-22 006. Six specimens were tested for each case and the averages were reported as the obtained results.



Figure 1: Tensile specimen, all the dimension in $\mathrm{mm}$

\section{Results and discussion}

Table 1: Mechanical Properties of Particleboard

\begin{tabular}{|c|c|c|c|c|}
\hline \multirow{7}{*}{ Particleboard } & $\begin{array}{c}\text { Weight } \\
\text { Fraction } \\
\text { Of Sago } \\
(\%)\end{array}$ & $\begin{array}{c}\text { Young } \\
\text { Modulus } \\
\text { (Mpa) }\end{array}$ & $\begin{array}{c}\text { Tensile } \\
\text { Strength } \\
\text { (Mpa) }\end{array}$ & $\begin{array}{c}\text { Impact } \\
\text { Strength } \\
(\mathrm{J} / \mathrm{m} 2)\end{array}$ \\
\hline \hline \multirow{5}{*}{$0.60 \mathrm{~mm}$} & & & & \\
& $90 \mathrm{wt} \%$ & 1181.75 & 5.23 & 22112.83 \\
& $85 \mathrm{wt} \%$ & 911.43 & 4.04 & 31737.04 \\
& $80 \mathrm{wt} \%$ & 883.71 & 3.91 & 46554.13 \\
& $75 \mathrm{wt} \%$ & 874.10 & 3.87 & 49214.15 \\
& $70 \mathrm{wt} \%$ & 766.47 & 3.39 & 51181.56 \\
\hline \multirow{5}{*}{$2.18 \mathrm{~mm}$} & $90 \mathrm{wt} \%$ & 2492.20 & 9.98 & 23648.56 \\
& $85 \mathrm{wt} \%$ & 2203.05 & 8.82 & 28574.16 \\
& $80 \mathrm{wt} \%$ & 1913.80 & 7.66 & 29482.03 \\
& $75 \mathrm{wt} \%$ & 989.75 & 3.96 & 39862.92 \\
& $70 \mathrm{wt} \%$ & 826.12 & 3.31 & 31131.06 \\
\hline & $90 \mathrm{wt} \%$ & 1141.10 & 4.17 & 22985.67 \\
& $85 \mathrm{wt} \%$ & 1266.15 & 4.62 & 38767.18 \\
& $80 \mathrm{wt} \%$ & 1998.50 & 7.30 & 36032.39 \\
& $75 \mathrm{wt} \%$ & 1869.95 & 6.83 & 27232.82 \\
& $70 \mathrm{wt} \%$ & 1741.40 & 6.36 & 20416.52 \\
\hline
\end{tabular}




\subsection{Mechanical properties}

\subsubsection{Young's modulus}

The performance of the Young's Modulus for the Sago/UF particleboard shown in Table1 were strongly dependent on the particle loading. The results show that the addition of matrix on the composite does not improve the young modulus. The Elasticity of the composite was strongly influenced by the fibre and matrix composition, fibre morphology, perfect fibre dispersion of individual particles in a specimen, aspect ratio of the single fibre, distribution of the fibres, fibre volume ratio, porosity and perfect adhesion between fibre-matrix [10,11].

By decreasing the weight fraction of the particleboard with particle size of $0.6 \mathrm{~mm}$ and $1.18 \mathrm{~mm}$, Young's Modulus decreases as the space between the particles had increased. This could be due to the fibre-matrix interface bonding quality which become weak when the matrix increased and particles decrease at the same times. According to the research, the inter connectivity of each phase in a composite become the main consideration during the test and the bonding characteristics of interface could affect the elastic modulus of the whole composite [12]. Elastic properties of individual phase and their concentration in a composite should take into account for the elastic properties of the composite materials [12].

Particles with the size of $1.18 \mathrm{~mm}$ showed the highest Young's Modulus at $90 \mathrm{wt} \%$ due to better fibre-matrix bonding and with high compaction of the specimen with small amount of voids.

Smaller particles, like $0.6 \mathrm{~mm}$, do not give good results on Young Modulus because it is difficult for the excess matrix to flow through the particles of the smaller size specimen. Besides, the strength of $0.6 \mathrm{~mm}$ particles is weaker compared to $1.18 \mathrm{~mm}$ particles and its will reduce the whole specimen strength.

For the coarse particle with $2 \mathrm{~mm}$ size, Young modulus increases with an increases in UF, reaching a maximum weight fraction at $80 \mathrm{wt} \%$ because the absence of voids in the composite create good bonding between the particles and matrix. The result dropped after that due to the decreased of Sago particles that created the void between each other and the excess matrix evaporated during the hot press process. The coarse particle had created a lot of voids between each other after $80 \mathrm{wt} \%$, therefore, when the specimen began to pull, it tends to fail easily as compare to other sizes.

Particleboard fabrication was depending on chemical and mechanical bonds of the materials because the matrix need to bind with the particles well between each other during the fabrication process. During the mechanical test, the applied stress can be effectively transferred between the particles and matrix due to the well bonded particles [11].

Young's Modulus of the sago UF particleboard were reduced with increase of matrix. These results imply that weight fraction and particles size has great influence on composite stiffness and specimens required higher volume of particles to substitute the voids [11].

\subsubsection{Tensile strength}

Based on the results shown in Table $1,0.6 \mathrm{~mm}$ and $1.18 \mathrm{~mm}$ particles had similar trend for the tensile strength, which slightly decreased by decreasing the weight fraction of Sago and this shows that the weight fraction has great influence on the tensile performance. The results show that $1.18 \mathrm{~mm}$ particles size at $90 \mathrm{wt} \%$ had the highest tensile strength.

The properties of the particle/matrix interfacial adhesion have great influence on the tensile strength performance and affect the stress transfer effectively [12]. Increasing the matrix will cause the tensile strength to reduce due to the poorly bonded particles between the hydrophobic polymeric matrix of Urea formaldehyde and the hydrophilic lignocellulose fillers that led to inefficient stress transfer [13]. Decreasing the weight fraction of particles caused the discontinuity of deboning that exists between the non-adherence of particle to polymer and caused the particle not be able to transfer the load during the test [11].

On the other hand, excessive matrix does not improve the tensile strength because it will cause the composite to become wet due to too much of moisture content in the composite and reduce the strength of bonding during the hot process. Besides, this could be due to the fact that high amount of water from matrix causes fibres swelling and creates gaps between the fibre and polymer-matrix and lead to a decrease in tensile properties.

The interaction of cellulose fibre with UF resin is excellent due to the hydrophilic nature of cellulose with UF matrix. The cellulose hydroxyl group and lignin hydroxyl groups are the major components of the fibre and both of the components play important role on hydrophilicity [14]. Hydrophilicity has great influence on the polymerization. Composite should be blended with the particles and matrix with the correct amount in order to create good chemical bonding between the particle and matrix in order to achieve the homogeneously dispersed in the composite. The performance of composites is determined by the particle/matrix interfacial adhesion and creates a good polymerization. This may indicate that the incorporation of Sago granules into the UF matrix introduces a new interfacial region that affects the stress transfer [15]. The dispersion of the networked UF with the Sago particles is expected to be good because its surface is covered with organic materials. The openings formed in the networked contributed to improve its dispersion by penetration of UF matrix into the particles and enhance the tensile strength at the same time [16].

\subsubsection{Impact strength}

Table 1 shows the impact strength behaviour of particleboard with different sizes at different weight fraction. The impact strength for $0.6 \mathrm{~mm}$ and $1 \mathrm{~mm}$ sieving 
size of particleboard increased linearly until 75\% weight fraction with decreasing the weight fraction of particle. However, the excessive matrix will reduce the impact strength. Impact strength for $2 \mathrm{~mm}$ sieving size was increased until $80 \%$ weight fraction as optimal strength and decreasing after that. The excessive matrix will not improve the impact strength. This is because the low particles content did not manage to dissipate the energy effectively. Chaharmahali et al mentioned that increasing the fibre content will significantly decrease the impact strength [17].

The optimal value to obtain the highest impact strength for $0.6 \mathrm{~mm}$ sieving size was $70 \% \mathrm{wt}$, while $1 \mathrm{~mm}$ and $2 \mathrm{~mm}$ were $75 \%$ wt of particleboard. $0.6 \mathrm{~mm}$ sieving size has better impact strength compared to $1 \mathrm{~mm}$ and $2 \mathrm{~mm}$ sieving size because $0.6 \mathrm{~mm}$ sieving size is more compactly filled in particleboard that provides a large region for stress concentration. The higher aspect ratios of sago particle had improved the structure of the panels [17].

$2 \mathrm{~mm}$ sieving size particleboard showed steep decline beyond their optimal values. This was due to higher particles content that led to higher particles contact. As a result, this led to poor interfacial bonding between the particles and matrix and hence decreased the mechanical properties. Thus, it can be said that the maximum particles content to allow the particles to be fully moistened by the matrix for all the sizes of particleboards were dependent to the optimum particles content. This explains why beyond the optimal weight fraction, the mechanical properties for all the sizes were experiencing steep decline [18]. According to Ishak et al. [18], the size of the particles affects the interfacial shear, normal stresses and fracture characteristics dramatically.

Besides, the most important factor that influences the mechanical properties of the sago plant is its chemical composition. According to Habibi et al. [19], sago particles contain cellulose, hemicellulose and lignin and are found to have a strong influence on the mechanical properties to the particles itself and the particleboard especially the cellulose content. Cellulose is the main structural component that provides strength and stability to the plant cell walls and the particles and the cellulose is one of the stiffest and strongest organic constituents in the natural fibres. Natural fibres play an important role in the impact resistance of fibre-reinforced composites as they interact with the crack formation and act as stress transferring medium [20].

\section{Conclusion}

From the obtained results, board performance had been greatly affected by the weight fraction. Particleboards with $1.18 \mathrm{~mm}$ with $90 \mathrm{wt} \%$ and $85 \mathrm{wt} \%$ met the M-2, $1.18 \mathrm{~mm}$ with $80 \mathrm{wt} \%$ met M-0,M-1\&M-S, $2 \mathrm{~mm}$ with $90 w t \%, 85 w t \%$ and $80 w t \%$ met the M-0, M-1 \& M$\mathrm{S}$ specification of American National Standard A208.12009 for Young's modulus. Resin loading and particle loading influenced the mechanical properties of the particleboard. Based on the experiment, excessive matrix does not promoted good mechanical properties and will increased the production cost at the same time. The new finding of the application may reduce the pressure on the forest resources and providing additional income to the farmer in Mukah Sarawak.

\section{References}

1. S.K.Nath. \& Vipin K. Chawla (2011) Wood substitution : recent development in India" J India Acad Wood Sci (2011) 8(2):68-71

2. Amer S. Singha \& Vijay Kumar Thakur, 2009 " Study of mechanical properties of ureaformaldehyde thermosets reinforced by pine needle power" Peer-reviewed article,bioresources.com 4(1), 292-308

3. Kristina oksman,2000 "Mechanical properties of natural fibre mat reinforced thermoplastic" Applied composite Materials 7:403-414

4. D.S.Awg-Adeni, S.Abd-Aziz, K.Bujang and M.A.Hassan (2010). Bioconversion of sago residue into value added products. African Journal Of Biotechnoloy, 9(14), pp.2016-2021

5. W.Y.Toh, J.C.Lai, W.A.R.Wan Aizan (2011). Influence of compounding methods on poly(vinyl) alcohol/sago pith waste biocomposites: mechanical and water absorption properties. Sains Malaysiana 40(7): pp.719-724

6. Amar Singh Singha \& Vijay Kumar Thakur (2008) " Effect of fibre loading on urea-formaldehyde matrix based green composites" Iranian Polymer Journal 17(11), 2008, 861-873

7. D.S.Awg-Adeni, S.Abd-Aziz, K.Bujang and M.A.Hassan(2010) " Bioconversion of sago residue into value added productsAfrican Journal Of Biotechnology 9(14), pp.2016-2021

8. JIS A 5908, (1994) Japanese Industrial Standard Particle Boards, Japanese Standards Association.

9. American Society for testing and Materials. Standard test method for charpy impact test. A370

10. Fabrice roussiere, Christophe baley, Gregory godard Dominique burr, 2012 "Compressive and tensile behaviour of PLLA Matrix composites reinforced with randomly dispersed flax fibres " Appl compos mater (2012) 19: 171-188

11. Shao-Yun Fu, Xi-Qiao Feng, Bernd Lauke, YiuWing Mai,2008, Effect of particle/matrix interface adhesion and particle loading on mechanical properties of particulate-polymer composites. Composites: Part B39 (2008) 933-961

12. Amer s.singha \& Vijay kumar Thakur, 2009 "Study of mechanical properties of urea-formaldehye thermosets reinforced by pine needle powder" Bio Resources 4(1),292-308

13. Takian Fakhrul and M.A.Islam, 2013," Degradation behaviour of natural fiber reinforced polymer matrix composites, SciVerse ScienceDirect 56(2013) pp.795-800

14. M.s.sreekala, M.G.Kumaran, Seena joseph \& Maya Jacob, Sabu Thomas, 2000," Oil palm fibre reinforced phenol formaldehyde composites: influence of fibre surface modifications on the 
mechanical performance" Applied composite materials 7: 295-329

15. Toh wen yee, Lai jau choy, Wan aizan wan abdul rahman,2011, “ Mechanical and water absorption properties of poly( vinyl alcohol) / sago pith waste biocomposites " Journal of composite materials, 2011 45:1201

16. Khalil ahmad, shaikh sirajuddin nizami, nudrat zahid raza, farzana habib, 2013 " The effect of silica on the properties of marble sludge filled hybrid natural rubber compisites" Journal of king saud university science, science 25 (2013),331-339

17. Majid chaharmahali, Jamal mirbagheri, Mehdi tajvidi, Saeed kazemi najafi, Yaser mirbagheri, 2010" Mechanical and physical properties of wood-plastic composite panels"Journal of reinforced plastics and composites, 29, no.2/2010
18. M.R.Ishak, Z.Leman, S.M.Sapuan, A.M.M.Edeerozey \& I.S.Othman 2010 " Mechnical properties of kenaf bast and core fibre reinforced unsaturated polyester composites" 9th National symposium on polymeric materials(BSPM2009)

19. Habibi, Y., El-Zawawy, W., Ibrahim, M M, Dufresne A 2008 Processing and characterization of reinforced polyethylene composites made with lignocellulosic fibres from Eqyptian agro-industrial residus Journal of Composites Science and Technology 68: 18771885

20. M.Jawaid, H.P.S.Adbul Khalil and A.Abu Bakar 2011 " Hybrid composites of oil palm empty fruit bunches/ woven jute fibre: chemical resistance, physical and impact properties" Journal of composite materials 